\title{
Prototype of Warehouse Automation System Using Arduino Mega 2560 Microcontroller Based on Internet of Things
}

\author{
Yusuf Kurnia') ${ }^{1}$ Jeksen Li Sie ${ }^{2)}$ \\ ${ }^{12)}$ Buddhi Dharma University \\ Jl.Imam Bonjol No. 41 Karawaci Ilir, Tangerang, Indonesia \\ 1)yusuf.kurnia@ubd.ac.id \\ 2) jeksen.lisie@gmail.com \\ Article history:
Received 10 November 2018;
Revised 18 November 2018; \\ Accepted 28 November 2018; \\ Available online 16 Desember 2018 \\ Keywords: \{use 4-6 keywords\}

\begin{abstract}
This research aims to collaborate between automation systems involving 3 main components namely Actuators, transducers / sensors, and microcontrollers are also implementations of IoT that are implemented in accessing, controlling, supervising, and monitoring all activities that are generally related to warehousing as well as increasing the efficiency and security of those who do not have the authority to access the room. In This research the hardware used as a control system is an integrated circuit board ARDUINO MEGA 2560 based on ATMega2560 Chipset that has $13 \mathrm{I} / \mathrm{O}$ pins for analog pins and 40 digital pins, the selection of that number of I/O pins as anticipated if this design will be developed further by using instruments that require hardware to support operational activities in specific warehouses of general, ESP8266 as a module device used for IoT communication using the Blynk application on Smartphone devices, and the RFID Mifare RC522 module used to access the room if there is an internet connection failure.
\end{abstract} \\ Automation Systems \\ IoT \\ Arduino Mega 2560 \\ Chipset STMega2560 \\ SmartPhone \\ Module RFID
}

\section{INTRODUCTION}

Internet of Things (IoT) is a hot topic discussed. This was triggered by the rapid development of electronic technology in various sizes other than that, electronic equipment in general is equipped with a network module that allows equipment or what is known as "Things" connected to the internet network [1].

The Internet of Things (IoT) offers interesting potential such as devices that can be controlled via smart phones between devices with one another that are interconnected remotely and notify conditions that are happening directly. In the modern industrial world, equipment can be designed to provide information about conditions from one device to another via the internet. With this system, we easily monitor and control the equipment used.

Automation systems play an important role in the modern industrial world, with the design of a good automation system, all things related to the industrial world can be run to be more economical and on target [2]. One topic of research is carried out by conducting experimental testing to improve security, automatic control, detection and monitoring, as well as supervision of the scope of warehousing.

\section{METHODS}

This research began with interviews, and continued with case studies, observations and experiments which began with the study of literature and questionnaires. The design of the mode control system can be made in two modes, namely online and offline, to access it in two ways, namely through a smartphone application using the Blynk platform when online devices and Mifare RC522 modules when the device enters in offline mode. 


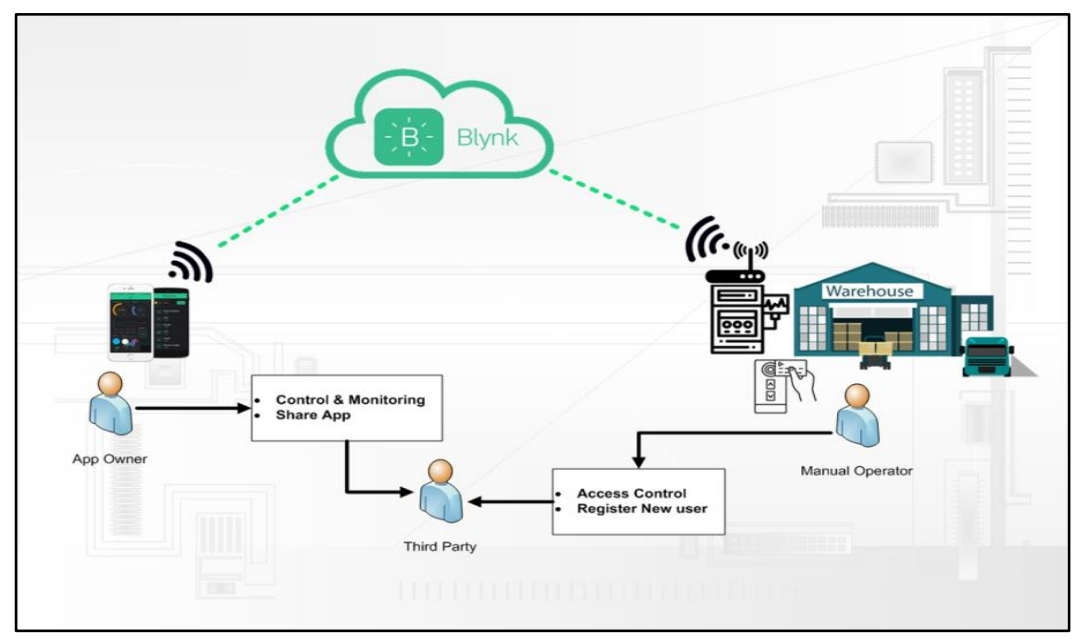

Fig 1. Distribution of Access Rights

The control system is designed when an activity is detected, the automation activities to turn on the lights and the fan turns on automatically, during operational activities, otherwise the lights and fans will turn off and the gates will close automatically. At the same time the control system is designed to monitor temperature conditions and detect smoke in a warehouse room.

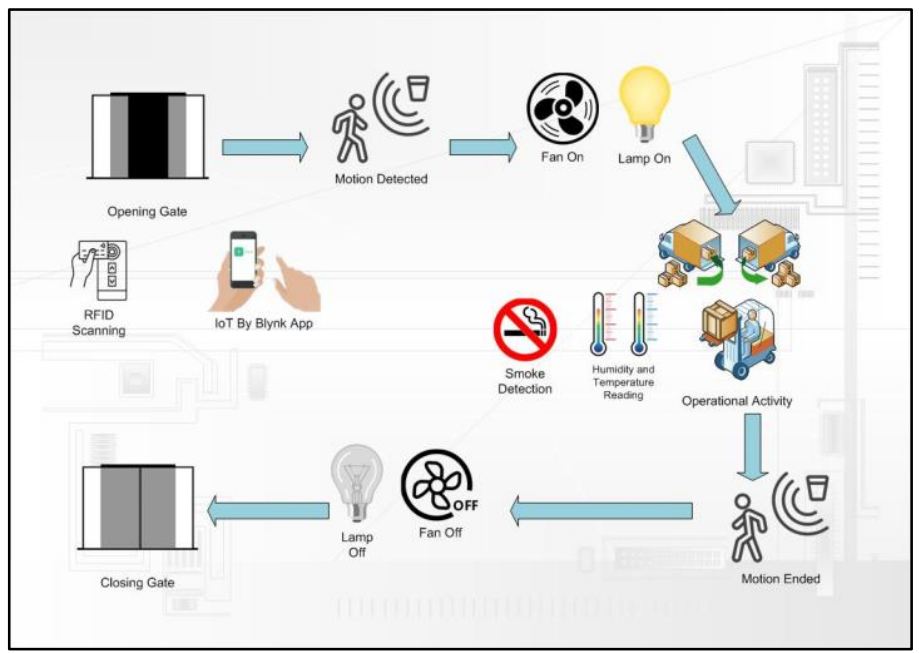

Fig 2. Device Running

The method used in solving the problem is the Internet of Things or control carried out without knowing the distance as long as the device is connected in an internet connection, which aims to monitor and control all components of the Sensor and Actuator. Whereas if the device is not connected in an internet connection, the method used for users accessing the room is using the Radio Frequency Identification or RFID method, a method of identification by using means of tags or labels mounted on objects to be identified.

The RFID method is also used to provide access rights to other parties to obtain warehouse access, using tags or labels registered by the Master Card owner.

The following is a description of the algorithm by using the flowchart the way it runs from the smart warehouse device to this research. 


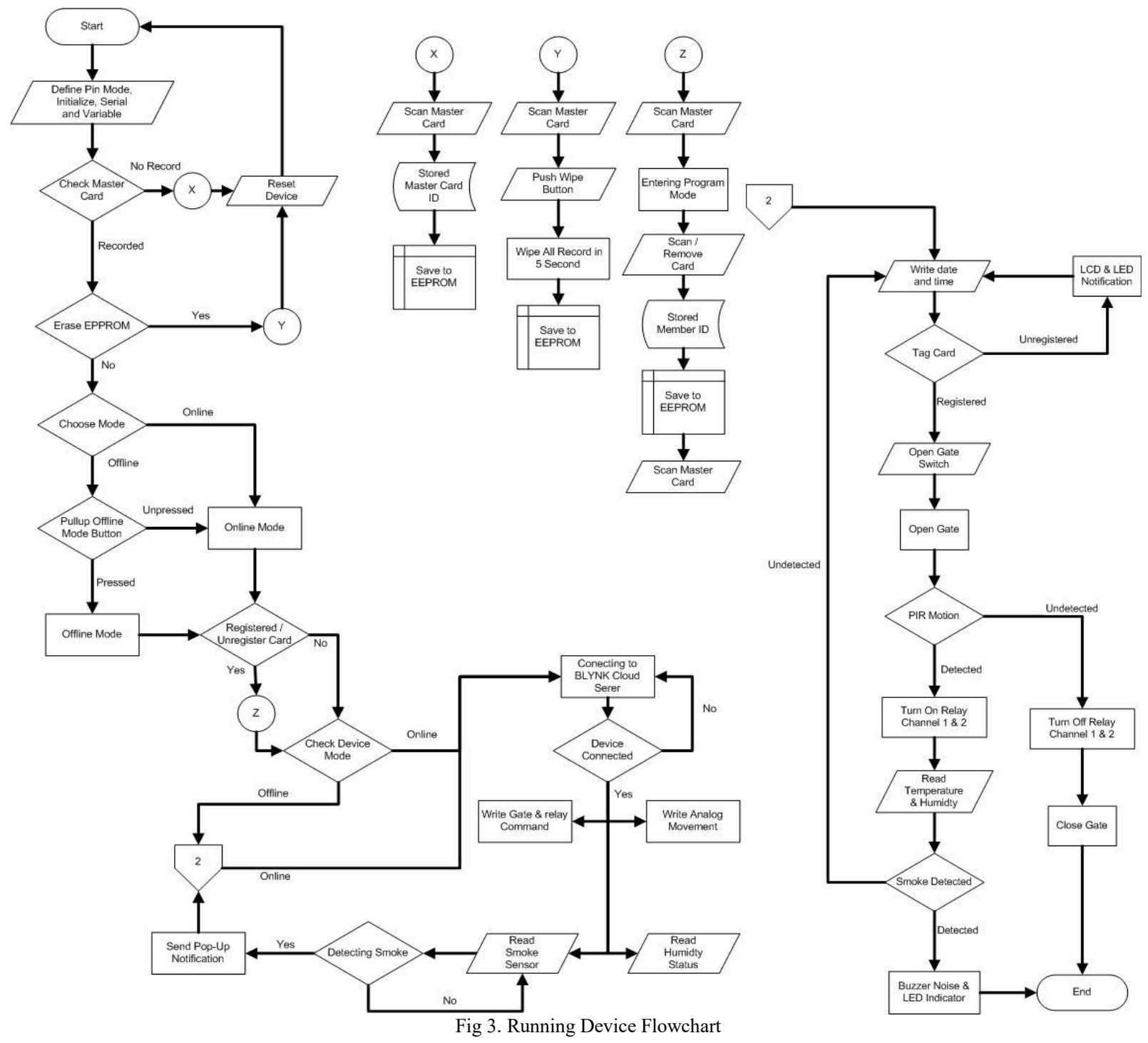

III. RESULTS

\section{Devices That Are Used Both Software and Hardware}

Arduino IDE

Arduino Integrated Development Environment or more commonly known as Arduino IDE is a text editor, compiler, uploader, serial port watcher, debugger that is provided free and runs on Windows, Linux and MAC OS platforms [3]. Arduino Mega 2560

ARDUINO MEGA 2560 is an ATmega2560 based microcontroller board. Having 54 digital I / O pins including 15 pins can be used as Pulse Width Modulation (PWM) output, 16 pins as analog input, 4 pins as UART (hardware serial port), using $16 \mathrm{MHz}$ crystal oscillator, USB connection, power supply connector with Jack type, ICSP header, and reset button [4].

\section{BLYNK}

Blynk is the easiest to use Internet of Things (IoT) platform, by providing a way to build mobile applications in minutes of Pradeeka Seneviratne. Drag-n-drop mobile application builders, on a variety of hardware ranging from prototype platforms such as Arduino and Raspberry Pi 3 to industrial classes ESP8266, Intel, Sierra Wireless, Particles, Texas Instruments, and several other hardware devices. Blynk was designed as an Internet of Things (IoT) application on smartphones, and there are three main components in the Blynk platform, namely Blynk App, Blynk Server, and Blynk Libraries [5].

\section{DHT11 Humidity Sensor}


DHT11 is a digital sensor used to measure temperature and humidity. This sensor has a very good level of stability. The calibration feature found on this sensor is also very accurate. Judging from the response, fast data reading and anti-interface capabilities, this sensor is a sensor that has the best quality. The sensor is widely used in temperature and humidity measurement applications because it has a signal transmission of up to 20 meters with a small size. The range of measurement distance for measurement of humidity is $20-90 \% \mathrm{RH}$ with an accuracy of $\pm 5 \% \mathrm{RH}$ while for the temperature measurement range is $0-50^{\circ} \mathrm{C}$ with an accuracy of $\pm 2{ }^{\circ} \mathrm{C}[6]$.

\section{ESP8266 Series ESP-01}

ESP-01 is the smallest module based on Espressif ESP8266EX Wi-Fi that can provide microcontroller access to Wi-Fi networks, and is a board that is quite popular in the ESP8266 module family [7].

\section{Mifare RC522 RFID Module}

MFRC522 is an Integrated Circuit product from NXP that uses a fully integrated $13.56 \mathrm{MHz}$ non-contact communication card chip that uses MIFARE higher transfer speeds of up to $848 \mathrm{kBd}$ from two directions to read and write, the device works with the RFID method. Radio Frequency Identification, better known as RFId, is a method of identifying objects using radio waves [8].

\section{MQ-9 Sensor}

MQ-9 Sensor is a sensor that works with the detection method using a low temperature cycle to detect carbon monoxide, the conductivity of the air sensor increases with increasing concentration of carbon monoxide gas, detecting flammable gases such as methane, propane and clean low temperature adsorption in the surrounding air [9].

\section{PIR Motion Sensor}

PIR (Passive Infrared Receiver) is a sensor based on infrared. In this PIR sensor there are parts that have their respective roles, namely Fresnel Lens, IR Filter, Pyroelectric sensors, amplifiers, and comparators. PIR sensors work by capturing heat energy generated from the passive infrared rays that every object has with the temperature of the object above absolute zero. This infrared beam is then captured by a pyroelectric sensor which is the core of this PIR sensor, causing a pyroelectic sensor consisting of gallium nitride, cesium nitrate and lithium tantalate to produce electric current [10].

\section{Stepper Motor}

A stepper motor is a DC motor that moves in separate steps. Has several scrolls arranged in groups called "Phases". By energizing each Phase in sequence, the motor will spin, one step at a time [11].

\section{Servo Motor}

A servo motor is a device or rotary actuator designed with a closed-loop (servo) feedback control system, so that it can be set-up or set to determine and ensure the angle position of the motor output shaft. A servo motor is a device consisting of a DC motor, a series of gears, a control circuit and a potentiometer. A series of gears attached to the DC motor shaft will slow the shaft rotation and increase the servo motor torque, while the potentiometer with changes in resistance when the motor rotates serves as a determinant of the position of the motor shaft rotation limit [12].

Explanation of designing a prototype with a wiring diagram to connect each device to a unified control system, which can be described as follows:

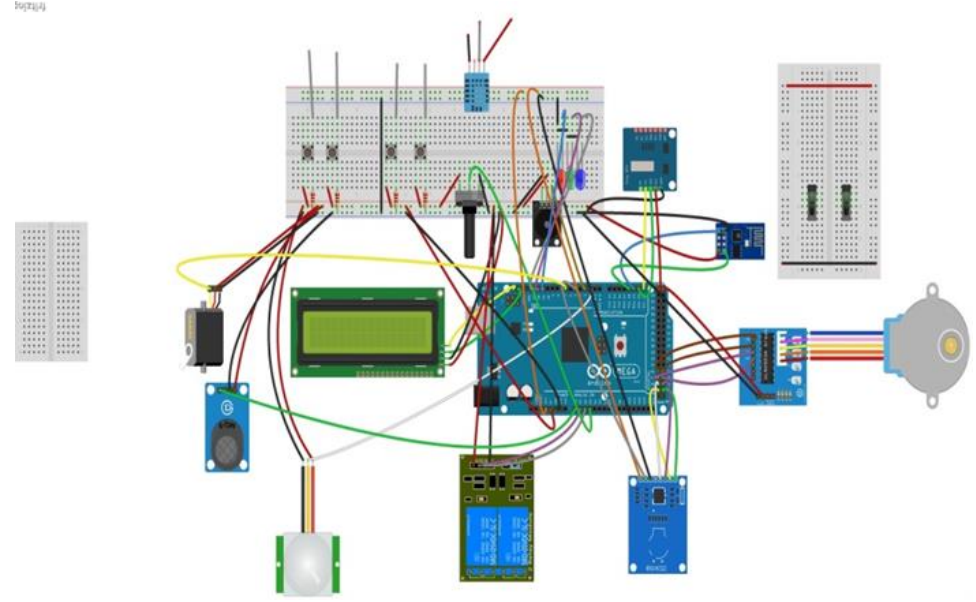

Fig 4. Wiring Diagram

The connection of each device to be connected to each other and can be operated as expected, the following connections can be described in table 1 below:

\begin{tabular}{|c|c|c|c|}
\hline Pin & Type & Module & Purpose \\
\hline $3 \mathrm{~V} 3$ & Power & & \\
\hline
\end{tabular}




\begin{tabular}{|c|c|c|c|}
\hline $5 \mathrm{~V}$ & & & \\
\hline Gnd & & & \\
\hline VIN & & & \\
\hline A0 & \multirow{4}{*}{ Analog } & Relay Channel 1 & Fan \\
\hline A1 & & Relay Channel 2 & LED \\
\hline A2 & & Potentiometer & Gate Speed Dimmer \\
\hline A3 & & MQ-9 Smoke Sensor & \\
\hline 2 & \multirow{12}{*}{ Pulse Width Modulation } & PIR Motion & \\
\hline 3 & & Tactile Switch & Close Gate \\
\hline 4 & & Tactile Switch & Open Gate \\
\hline 5 & & Reset RC522 & \\
\hline 6 & & Servo X & CCTV Bracket Navigation \\
\hline 7 & & Servo Y & CCTV Bracket Navigation \\
\hline 8 & & Servo Z & Gate Key \\
\hline 9 & & Buzzer & \\
\hline 10 & & DHT11 & \\
\hline 11 & & Red LED & \\
\hline 12 & & Green LED & \\
\hline 13 & & Blue LED & \\
\hline INT0 & \multirow{4}{*}{ Interrupt Pin } & LCD1602 SCL & SCL \\
\hline INT1 & & LCD1602 SDA & SDA \\
\hline 18 & & ESP-01 TX & $\mathrm{RX}$ \\
\hline 19 & & ESP-01 RX & TX \\
\hline 20 & \multirow{14}{*}{ Pulse Width Modulation } & Tinny RTC SDA & SDA \\
\hline 21 & & Tinny RTC SCL & SCL \\
\hline 42 & & NC Limit Switch & NC Close \\
\hline 43 & & NO Limit Switch & NO Close \\
\hline 44 & & NC Limit Switch & NC Open \\
\hline 45 & & NO Limit Switch & NO Open \\
\hline 46 & & ULN2003 IN1 & \\
\hline 47 & & ULN2003 IN3 & \\
\hline 48 & & ULN2003 IN2 & \\
\hline 49 & & ULN2003 IN4 & \\
\hline 50 & & RC522 MISO & MISO \\
\hline 51 & & RC522 MOSI & MOSI \\
\hline 52 & & RC522 SCK & SCK \\
\hline 53 & & RC522 SS & SS \\
\hline
\end{tabular}

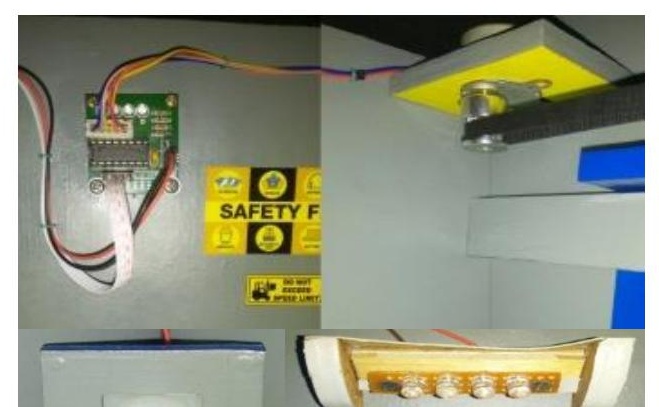


In figure 5 the stepper motor is the driving motor for opening and closing the gate, when the PIR motion detects that there is activity, the lights and fan will be turned on automatically during operational activities in the operational warehouse space and cardboard storage room.

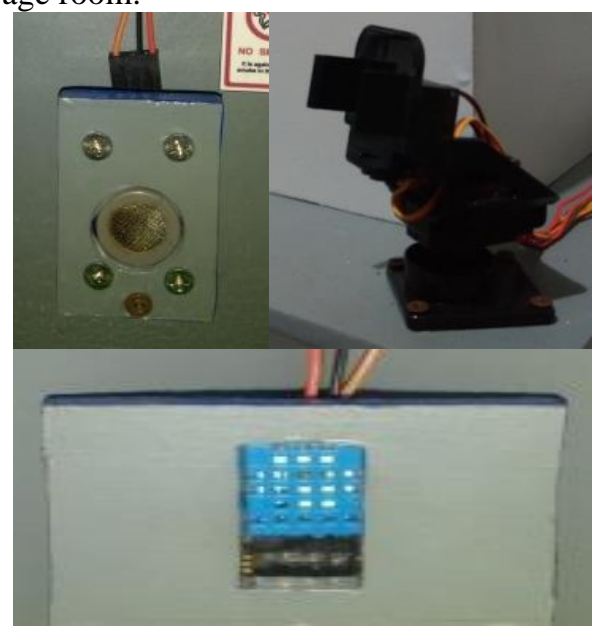

Fig 6. MQ-9, Servo Motor, DHT11

In figure 6 the DHT11 sensor is used to monitor the temperature in the storage room for raw material for thinner, the MQ-9 sensor is used to detect smoke in the cardboard storage room, while the servo motor is a visualization to move the CCTV bracket as an increase in surveillance.

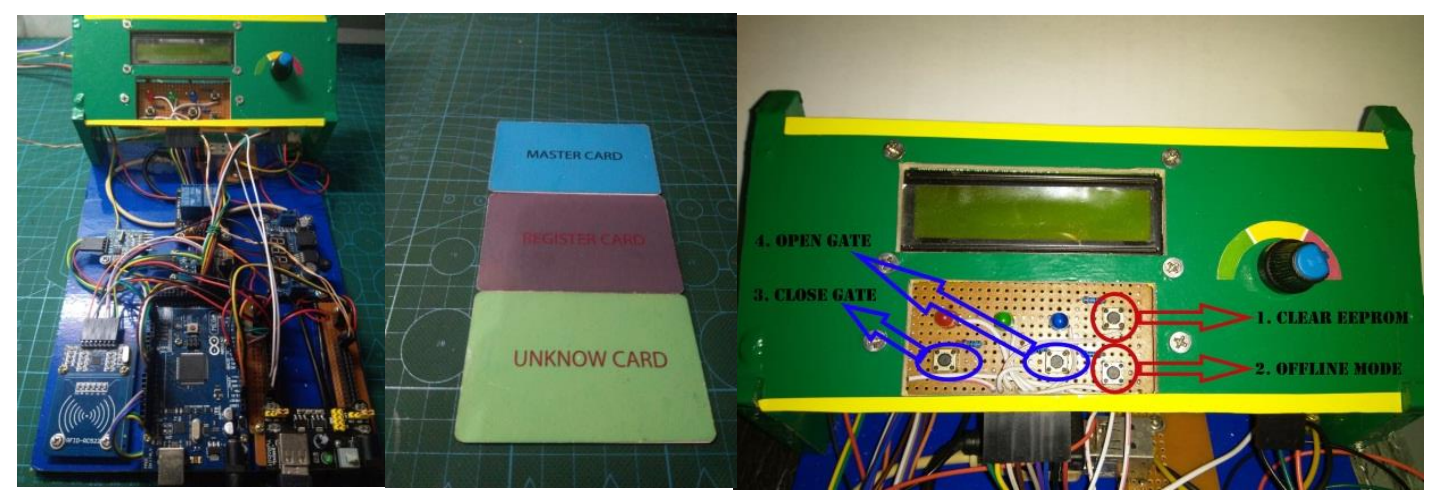

Fig 7. Panel Sistem Kendali dan kartu RFID

In Figure 7 Panel Control system that is connected to the Arduino Mega 2560 and Mifare MC522 to access the RFID method, there are various buttons that are used for manual operation if there are obstacles to the internet connection so that the device is connected, only the card that has been tagged uses the permitted master card access. 


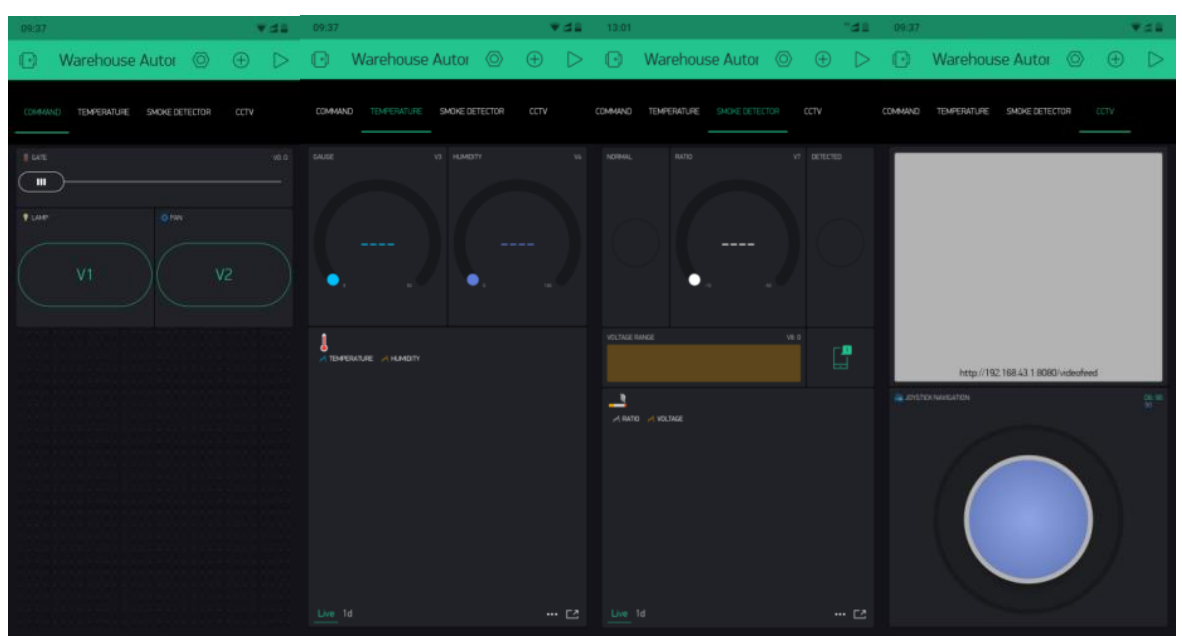

Fig 8. Blynk App

In Figure 8 Blynk App contains widgets on each tab to control, monitor, and monitor the IoT method, from gate control, fans and lights, temperature monitoring and smoke detection activities to the room, and CCTV surveillance which bracket can be positioned.

\section{CONCLUSIONS}

Conclusions that can be generated from this research, namely automation activities work well when there is activity or vice versa detected by the PIR sensor. Smoke detection and room temperature monitoring can be displayed through the smartphone application and device display. The system can run with both Online and Offline. Applications can be controlled by parties that are given access through the QR Code and the distribution of RFID Card Access Rights can be shared by tagging the cards that you want to share with other parties so that they are stored in the system to access the room gate.

The suggestion that can be given for the development of this system is the need to calculate electricity power consumption if implemented on devices that use AC electricity. Development of flexible SSID and Password addressing when the device tries to connect to a new connection, without the need to re-upload syntax into EEPROM, establishing a local server as an anticipation if the internet connection is offline but the system wants to be controlled via a smartphone, selecting an LCD screen that contains maNY CHARACTERS AS FEEDBACK INPUT/output interface of the system.

\section{REFERENCES}

[1] Kurniawan, A. (2016). Mengenal Microsoft Azure IoT. Jakarta: Elex Media Komputindo. 1.

[2] Vongbunyong, S., \& Chen, W. H. (2015). Disassembly Automation Automated Systems with Cognitive Abilities. Switzerland: Springer. 25.

[3] Eko Prasetyo, Data Mining Mengolah Data Menjadi Informasi Menggunakan Matlab. Penerbit ANDI, pp. 50-71.

[4] Arduino. (2017, April 14). ARDUINO MEGA 2560 REV3. Dipetik November 2018, 11, dari Arduino: https://store.arduino.cc/usa/arduinomega-2560-rev3.

[5] Seneviratne, P. (2018). Hands-On Internet of Things with Blynk: Build on the power of Blynk to configure smart devices and build exciting IoT projects. Birmingham: Packt Publishing.6.

[6] Hafiz, A., Fardian, \& Rahman, A. (2017). Rancang Bangun Prototipe Pengukuran dan Pemantauan Suhu, Kelembaban serta Cahaya Secara Otomatis Berbasis Iot pada Rumah Jamur Merang. KITEKTRO, 51-57.

[7] Seneviratne, P. (2017). ESP8266 Robotics Projects: DIY Wi-Fi controlled robots. Birmingham: Packt Publishing Ltd.8.

[8] Setiawan, E. B., \& Kurniawan, B. (2015). Perancangan Sistem Absensi Kehadiran Perkuliahan dengan Menggunakan Radio Frequency Identification (RFId). Jurnal CoreIT, Vol.1, 44-49.

[9] seeedstudio. (2018, March 3). Grove - Gas Sensor(MQ9). Dipetik November 11, 2018, dari seeedstudio: http://seeedstudio.com/GroveGas_Sensor-MQ9

[10] Ahadiah, S., Muharnis, \& Agustiawan. (2017). Implementasi Sensor Pir Pada Peralatan Elektronik Berbasis Microcontroller. INOVTEK POLBENG, 29-34.

[11] Earl, B. (2014, May 5). What is a Stepper Motor? Dipetik November 24, 2018, dari Adafruit: https://learn.adafruit.com/all-about-steppermotors/what-is-a-stepper-motor.

[12] Dermanto, T. (2014, March 19). Pengertian dan Prinsip Kerja Motor Servo. Dipetik November 2018, 14, dari Desain Sistem Kontrol: http://trikueni-desain-sistem.com/2014/03/Pengertian-Motor-Servo.html 